\title{
Courting Social Justice: JUdicial ENFORCEMENT OF SOCIAL AND Economic Rights in DeVeloping World
}

\author{
Varun Gauri e Daniel M. Brinks (Orgs.) \\ Cambridge University Press, Cambridge, 2008
}

Fabiola Fanti(*)

Basta abrir os jornais para se constatar que as cortes têm sido cada vez mais chamadas a decidir questões envolvendo políticas traçadas pelos Poderes Legislativo e Executivo, ocupando, assim, um espaço na arquitetura institucional das democracias contemporâneas que tradicionalmente não Ihes cabia. Tal interferência dos tribunais em temas que normalmente não the eram afeitos possui várias facetas, que vão desde uma intervenção mais ampla, como, por exemplo, em planos de reforma do Estado e políticas públicas de âmbito nacional colocadas em curso pelos governos ou casas legislativas, como em casos mais específicos, de efetivação individual de direitos sociais por meio de ações judiciais.

No contexto deste fenômeno, que envolve discussões ligadas ao papel do Poder Judiciário nas democracias contemporâneas e as consequentes tensões geradas entre o direito e a política, tem crescido também o debate acadêmico sobre o tema. Trabalhos realizados no âmbito da ciência política, direito e saúde pública buscam enfrentar as questões trazidas por esta realidade. Neste sentido, os enfoques dados aos estudos dentro e fora do Brasil são os mais variados e vão desde da abordagem da questão do controle de constitucionalidade exercido por cortes superiores até o enforcement de direitos através da justiça comum.

No caso específico deste segundo tipo de abordagem, importantes pesquisas têm sido produzidas, trazendo ao debate estudos empíricos que analisam a influência das cortes na efetivação de direitos sociais e nas políticas públicas a eles relacionadas. Boa parte dessas investigações, realiza-

(*) Mestranda em Ciência Política e especialista em Direitos Humanos pela Universidade de São Paulo (USP), pesquisadora do Núcleo de Direito e Democracia do Centro Brasileiro de Análise e Planejamento (CEBRAP) e da Escola de Direito da Fundação Getúlio Vargas (FGV/EDESP), no programa de pósgraduação lato sensu do GVlaw. Email: <biolafanti@yahoo.com.br>. Recebido em: 20.02.09. 
das em países em desenvolvimento como África do Sul, Brasil, Argentina ou Índia, abordam o tema da crescente procura do Judiciário como um caminho para garantia do direito à saúde. Especificamente no caso brasileiro, o tema mais abordado são as ações judiciais contra o Poder Executivo para fornecimento de medicamentos, tratamentos ou insumos. Em linhas gerais, tais trabalhos buscam entender as mais variadas questões que envolvem o problema, que vão desde a adequação das decisões, tendo em vista a justiça distributiva, até os efeitos causados por elas nas políticas governamentais que cuidam da questão.

É neste cenário que se insere o livro ora resenhado - Courting social justice: judicial enforcement of social and economics rights in developing world. Trata-se de um estudo empírico comparado, realizado em cinco países em desenvolvimento, que busca entender o processo que envolve a tutela judicial dos direitos sociais e econômicos e seus reflexos na política governamental. Em outras palavras, os autores buscam entender qual é o papel e o impacto das cortes na realização dos direitos sociais e econômicos em países em desenvolvimento. A pergunta central que o livro se propõe a responder é quão desejável é o uso das cortes para se efetivar direitos sociais e econômicos ou em que medida esse processo pode trazer avanços na garantia de tais direitos.

Para atingir esses objetivos, o livro foi estruturado em oito capítulos, sendo que cinco deles correspondem a estudos empíricos realizados nos países em desenvolvimento selecionados para a pesquisa, quais sejam: África do Sul, Brasil, Índia, Nigéria e Indonésia. Pesquisadores de cada uma dessas localidades traçam, a partir de uma metodologia comum, estudos detalhados de como se dá o envolvimento dos tribunais no processo de elaboração e execução de políticas públicas por meio de decisões a respeito de direitos sociais. Os estudos empíricos são focados na litigância por diretos à saúde e à educação.

Os países escolhidos possuem diferentes características em vários aspectos: utilizam o sistema common ou civil law; possuem constituições mais recentes ou antigas; são democracias mais jovens ou velhas; fazem controle de constitucionalidade abstrato, difuso ou híbrido; têm índices agressivos ou incipientes de litigância em direitos sociais e econômicos; além de diferenças na capacidade do Estado e renda nacional. Essa variação, segundo os organizadores, é necessária para que se avalie em que medida as condições sociais, econômicas, políticas e institucionais dos países favorecem o envolvimento do Judiciário e o impacto de suas decisões em questões envolvendo direitos sociais e econômicos.

Assim, no capítulo que abre o livro, os organizadores buscam apresentar uma estrutura conceitual para explicar o envolvimento do Poder Judiciário em políticas públicas. $\mathrm{O}$ objetivo deste esforço é não só entender melhor as questões que envolvem o problema, como também criar um vetor comum entre as análises realizadas em cada um dos países presentes no livro, com o intuito viabilizar a comparação entre elas na conclusão. 
Para tanto, é descrito o "ciclo de vida da litigância em políticas públicas", formado por quatro estágios: (i) a proposição de casos nas cortes, denominado legal mobilization; (ii) a decisão judicial; (iii) a resposta da burocracia, órgão político ou parte privada envolvida na decisão judicial, à decisão da corte; e, eventualmente, (iv) a continuidade da ação pelas partes, por meio de recursos. O resultado desse processo é o que os autores chamam de legalization of policy em áreas específicas de políticas públicas. Este fenômeno é entendido como aquele em que tanto as cortes, advogados e demandantes se tornam atores relevantes, assim como a linguagem e as categorias do direito se tornam conceitos importantes no desenho e implementação de políticas públicas. Esta compreensão de legalization of policy é central para os organizadores, os quais, apesar de assumirem a dificuldade de mensurá-la com precisão, acreditam que ela seja ampla o suficiente para identificar os aspectos mais interessantes do papel do direito e das cortes na esfera das políticas públicas.

A definição de legalization of policy reconhece uma natureza aberta e interativa das decisões judiciais nos casos envolvendo políticas públicas. Assim, há uma influência mútua entre as escolhas feitas pelos atores relevantes em cada um dos estágios do processo descrito acima - as cortes e suas decisões estão implicadas neste conjunto de interações estratégicas. Vale dizer que, segundo os organizadores do livro, as cortes não proferem decisões isoladas, sem diálogo com os outros Poderes, apropriando-se de funções que não são suas - como em geral é retratado na literatura sobre o assunto - mas, representam mais um ator relevante na solução das demandas a elas apresentadas. Neste sentido, os organizadores argumentam que os tribunais, por meio de tal diálogo, podem contribuir para a superação de bloqueios políticos, configurar importantes canais de informação para atores da burocracia, criar espaço para a deliberação e compromisso entre interesses conflitantes e fazer com que o Estado se torne responsável em cumprir compromissos que não implementou, ou que o fez parcialmente.

Os capítulos do livro que se seguem trazem os já mencionados estudos empíricos realizados na África do Sul, Brasil, Índia, Nigéria e Indonésia a respeito de como se dá a litigância envolvendo os direitos à saúde e educação e os consequentes impactos trazidos pelas decisões das cortes nas políticas públicas sociais. Tais trabalhos, se por um lado utilizam a noção de legalization of policy e os quatro estágios do chamado "ciclo de vida da litigância em políticas públicas" apresentadas na introdução, por outro também apresentam especificidades do processo tal qual como ocorre em cada um dos países selecionados. Assim, ao mesmo tempo em que se encontram experiências similares e fenômenos que podem trazer comparações muito interessantes a respeito do tema estudado no livro, também é possível identificar diferenças que trazem aspectos fundamentais para uma melhor compreensão da litigância em direitos sociais.

A este trabalho de condensar as experiências relatadas em cada um dos países estudados, é dedicada a conclusão do livro. Por meio da compa- 
ração entre os resultados neles encontrados, os organizadores buscam explicar a variação nos níveis de mobilização para exigir os direitos à saúde e educação em juízo (legal mobilization), nas áreas de políticas públicas demandadas e nas estratégias judiciais utilizadas para, em seguida, procurar entender as causas de tais variações. O próximo passo é apontar quem se beneficia direta e indiretamente com os efeitos da litigância por tais direitos. Ainda discutem o papel das cortes nas democracias contemporâneas, antes de, finalmente, responder à questão que permeia toda a obra, qual seja, se de fato as cortes podem trazer avanços na efetivação dos direitos sociais e econômicos. Em linhas gerais, feita uma série de observações apresentadas nas últimas páginas da conclusão, os organizadores veem de forma positiva o envolvimento das cortes em demandas concernentes a direitos sociais.

Apresentada a obra de forma panorâmica, cabe ainda tecer algumas considerações a seu respeito. Primeiramente, vale ressaltar a valorosa contribuição que as pesquisas empíricas nos cinco países em desenvolvimento sobre o processo de influência das cortes em políticas públicas sociais de saúde-educação, apresentadas de forma comparada, trazem sobre este tema. Muitos trabalhos foram realizados no sentido de descrever o envolvimento dos tribunais na revisão de legislação ou de amplas políticas governamentais, mas nenhum havia se debruçado ainda sobre a questão envolvendo direitos sociais, a despeito da crescente importância do tema.

Outro ponto muito interessante do livro é a busca dos organizadores e demais autores por uma compreensão global das causas e consequências da litigância em direitos sociais e econômicos, que vai além da simples constatação de características do problema encontradas localmente. Este objetivo leva-os à procura da identificação de elementos estruturais do processo que possam explicá-lo de forma mais ampla, dando a ele unidade analítica, o que vai além de análises apenas descritivas do fenômeno.

Soma-se a isso uma diferença relevante em relação à parte da literatura que trata do tema: de maneira geral os organizadores e autores não dão centralidade na obra a argumentos normativos clássicos sobre a questão da litigância em direitos sociais, como, por exemplo, a separação de poderes, a discricionariedade do Poder Judiciário para interferir em políticas públicas e sua legitimidade democrática para fazê-lo. Assim, é dada uma nova abordagem ao fenômeno, trazendo ao debate outras questões, e foge-se de discussões de caráter eminentemente normativo que priorizam o "dever ser".

Finalmente, deve-se ressaltar o entendimento positivo e, em certa medida original, dado pelos organizadores à litigância em direitos sociais. Os organizadores veem neste fenômeno de envolvimento das cortes em questões tradicionalmente políticas um processo de composição entre os Poderes e não de antagonismo, o que leva a melhoras na elaboração e prática das políticas públicas, trazendo avanços na efetivação de tais direitos. 